\title{
Associations of dietary inflammatory index, serum levels of MCP- 1 and body composition in Iranian overweight and obese women: a cross-sectional study
}

Nasim Ghodoosi ', Atieh Mirzababaei ', Elahe Rashidbeygi', Negin Badrooj', Seyedeh Forough Sajjadi', Leila Setayesh ${ }^{1}$, Mir Saeed Yekaninejad ${ }^{2}$, Seyed Ali Keshavarz ${ }^{3}$, Farideh Shiraseb ${ }^{1}$ and Khadijeh Mirzaei ${ }^{1^{*}}$ (i)

\begin{abstract}
Objective: Although, several studies have illustrated that there is a relation between dietary inflammatory index (DII) with obesity-related parameters, and inflammation, their results were controversial. This study aimed to investigate this relationship among Iranian women.

Results: Multivariable linear regression showed that fat mass was $0.14 \mathrm{~kg}$ lower in the anti-inflammatory diet group, with respect to the pro-inflammatory group, after adjusting covariates such as age, physical activity, economic and job status ( $\beta=-0.142,95 \% \mathrm{Cl}-4.44,-1.71, P=0.03$ ). Fat-free mass (FFM) was $1.5 \mathrm{~kg}$ more in the anti-inflammatory diet group, compared to the pro-inflammatory diet group, after adjusting for potentials cofounders $(\beta=1.50,95 \% \mathrm{Cl}$ $0,3.01, p=0.05)$. Furthermore, after adjusting for potentials cofounders, it was revealed that the subjects with lower Dll had lower monocyte chemoattractant protein-1 (MCP-1) levels in serum $(\beta=-18.81,95 \% \mathrm{Cl}-35.84,-1.79$, $p=0.03$ ). These findings suggest an inverse and significant relationship between DII and FFM and also DII is directly related to Fat mass and the level of MCP-1. This finding can be used for developing interventions that aim to promote healthy eating to prevent inflammation and non-communicable disease development among obese females.
\end{abstract}

Keywords: Dietary inflammatory index, Overweight, Obesity, Body composition, Body fat mass, Fat-free mass, MCP-1

\section{Introduction}

Over the past 3 decades, the prevalence of obesity has nearly doubled worldwide [1]. The mean Body mass index(BMI) for women rose by $0.5 \mathrm{~kg} / \mathrm{m}^{2}$ per decade from 1980 to 2008 globally [2]. Notably, it has been suggested that more than $21 \%$ of women will be obese by 2030 internationally [3]. Obesity results in inflammation

\footnotetext{
*Correspondence: mina_mirzaei101@yahoo.com

1 Department of Community Nutrition, School of Nutritional Sciences and Dietetics, Tehran University of Medical Sciences (TUMS), P.O. Box: 14155-6117, Tehran, Iran

Full list of author information is available at the end of the article
}

cascade [4] and increased the risk of cardiovascular disease (CVD), hypertension (HTN), and stroke [5-8].

Obesity is contributed to low-grade systemic inflammation however, the exact underlying molecular pathway did not understand completely. It has been proposed, however, that this inflammation is created by pro-inflammatory cytokines produced by infiltrated macrophages in adipose tissue [9-11]. The underlying mechanism can be explained by penetration macrophage into adipose tissue, some chemotactic molecules such as monocyte chemoattractant protein-1 (MCP-1), are secreted by white adipose tissue (WAT) [12]. MCP-1 is known as the main ligand of chemokine receptor-2 (CCR2) [13] That plays an important role in obesity-induced inflammatory 
responses [14]. MCP-1 levels have been related to many diseases, such as CVD, diabetes [15-17]. Recent studies showed that MCP-1 levels can be decreased by an antiinflammatory diet, such as a Mediterranean diet $[18,19]$.

Based on the consumption of 45 specific foods and nutrients, dietary inflammatory index (DII) demonstrates the serum levels of six inflammatory biomarkers [Interleukin1beta (IL-1 $\beta)$, Interleukin 4 (IL-4), Interleukin 6 (IL-6), Interleukin 10 (IL-10), Tumor necrosis factoralpha (TNF $\alpha$ ), and C-reactive protein (CRP)] [20]. Moreover, many studies revealed that healthy and unhealthy dietary index such as a vegetarian diet is associated with anthropometric measures or body composition. [21-24]. To our knowledge, a limited number of studies have investigated the relationship between DII, body composition, and serum MCP-1 nevertheless, this association had not been evaluated in Iran. Consequently, the present study decided to assess the relationships between DII with MCP1 and body composition.

\section{Main text \\ Methods \\ Study design and population}

A cohort of 280 non-postmenopausal and healthy women aged $18 \leq$ years, who referred to health centers in Tehran, Iran, in 2018 was recruited in this cross-sectional study. Multistage cluster random sampling method was used to select certain regions from among all the regions of the city; finally, 20 clusters were chosen to select the obese and overweight participants (BMI: $25-40 \mathrm{~kg} / \mathrm{m}^{2}$ ). The exclusion criteria were as follows: a history of any acute or chronic diseases such as hypertension, CVD, diabetes mellitus, hepatic or renal disease or alcohol consumption, regular usage of medicine other than birth control pills, pregnancy, or lactation. They were excluded if adhered to special dietary patterns or had any significant body weight fluctuations over the past year.

\section{Dietary measurements \& DII calculation}

Dietary assessment was carried out by a validated and reliable 147-item semi-quantitative food frequency question (FFQ) designed according to the Willett study that administered by a trained nutritionist to assess the average daily intake for last year [25]. The FFQ consisted of a list of foods with standard serving sizes. Participants were asked to report their frequency and the amount of each food item consumed during the previous year on a daily (e.g., bread), weekly (e.g., rice, meat), or monthly (e.g., fish) basis. Household measures were used to convert portion sizes of the consumed foods into grams [26], and an estimated average daily intake of food parameters was calculated from the FFQ using NUTRITIONIST IV software (version 7.0; N-Squared Computing, Salem,
OR). FFQ-derived dietary data were used to calculate DII scores for all participants. The dietary data were linked to the regionally representative world database that included food consumption from eleven populations around the world and provided a robust estimate of a mean and standard deviation for each parameter [27]. In order to get $\mathrm{z}$-scores, the "standard global mean" was subtracted from the actual dietary intake amount, and this value was divided by the standard deviation. Subsequently, to minimize the effect of 'right skewing', these $\mathrm{z}$-scores were converted into a percentile - each percentile score was doubled and then subtracted by 1 . The centered percentile score for each food parameter for each individual was then multiplied by the respective food parameter effect score, to obtain a food parameterspecific DII score for an individual [27]. Subsequently, all of the food parameter-specific DII scores were summed together to calculate the overall DII score. Higher DII scores indicated a more pro-inflammatory diet; whereas lower values represented more anti-inflammatory diets [27]. A total of 29 food parameters were available from the FFQ, were used to calculate DII (namely: energy, carbohydrate, protein, total fat, monounsaturated fat, polyunsaturated fat, saturated fat, omega-3, omega- 6 fatty acids, cholesterol, fiber, thiamin, riboflavin, niacin, vitamin B6, folic acid, vitamin B12, iron, magnesium, selenium, zinc, $\beta$ carotene, vitamin $A, C, D, E$ and tea, onion, caffeine).

\section{Biochemical assessment}

All Biochemical analyses were carried out on venous blood samples that were collected after $12 \mathrm{~h}$ fasting, and the serum was centrifuged, liquated, then stored at $-80{ }^{\circ} \mathrm{C}$. Serum MCP-1 levels were measured by the enzyme-linked immunosorbent assay (ELISA) method with an appropriate kit (Zell Bio GmbH, ULM, Germany, assay range: $5 \mathrm{ng} / \mathrm{L}-1500 \mathrm{ng} / \mathrm{L}$, sensitivity: $2.4 \mathrm{ng} / \mathrm{L}$, inter-assay variability: $\mathrm{CV}<12 \%$, intra-assay variability: $\mathrm{CV}<10 \%)$.

\section{Anthropometric assessment}

Bioelectrical impedance analysis (BIA) (InBody 720, Korea) was utilized to calculate body composition measures, including body fat mass and fat-free mass. Anthropometric measures such as body weight, BMI, waist circumferences (WC), and waist-hip ratio (WHR) were measured for all participants. Height was characterized while the subjects were in a standing position without shoes, in contact with the wall with their head, shoulders, heels, and hips, and their height was recorded to the nearest $0.1 \mathrm{~cm}$ with Seca 206. All of the measurements were done by expert trained technicians and based 
on specific guidelines, in order to reduce interpersonal variation.

\section{Physical activity assessment}

The required information on physical activities in three levels of mild, moderate, and vigorous for research purpose was achieved by using The International Physical Activity Questionnaire (IPAQ) which can be applied by young and middle-aged adults (18-65years). All these sub-components were summed across MET scores and MET-minutes per week (MET-min/wk) were computed and then the total physical activity from all activity categories was reported [28].

\section{Statistical analyses}

DII (dichotomous) was examined across the quantitative characteristics. These were analyzed through an independent sample T-test. Linear regression analyses were conducted to determine the relationship between DII score with fat-free mass and serum MCP-1 levels, adjusted for potential confounding factors. The results are reported as a percentage change $(\beta)$, with $95 \%$ confidence intervals $(95 \% \mathrm{CI})$. P values of $<0.05$ were considered to be statistically significant. Statistical analysis was performed using SPSS version 21 (SPSS Inc., Chicago, USA).

\section{Results}

\section{Study population characteristics}

The DII score in this study ranged from -4.14 (most anti-inflammatory score) to 3.89 (most pro-inflammatory score). DII was categorized based on the median value of the DII (0.05). A total of 280 females were categorized, based on the DII level, into the anti-inflammatory diet $(\mathrm{DII} \leq 0.05)$ and the pro-inflammatory diet $(\mathrm{DII}>0.06)$ groups. Participant characteristics by DII categories are provided in Table 1. There were no significant differences observed in participant characteristics across the two DII groups. Notably, there were significant differences in fat-free mass $(P=0.021)$ among DII group members and MCP-1 serum levels and physical activity among the DII categories $(P<0.0001)$.

DII food parameters intakes across the anti-inflammatory and pro-inflammatory diet are shown in Table 2. No significant differences were noted regarding energy intakes between DII groups (Table 2). However, among DII groups, some nutrient intakes, such as total fat $(P=0.013)$, saturated fatty acid (SFA), polyunsaturated fatty acid (PUFA), monounsaturated fatty acid (MUFA), omega- 6 fatty acids, and Vitamin $\mathrm{E}(P<0.0001)$ was higher with those in the pro-inflammatory group, whereas riboflavin $(P=0.021)$, Vitamin $C(P=0.031)$ and Beta-carotene $(P<0.0001)$ were lower intakes mean in the pro-inflammatory diet group compared to the antiinflammatory diet group (Table 2).

Results obtained from modeling DII as a dichotomous variable in relation to the fat-free mass showed a negative association and positive association between DII adherence and fat-free mass and fat mass respectively, after adjustment for age, physical activity, economic and job status $(P=0.05, P=0.03)$ (Table 3$)$. As shown in Table 3 , the fat-free mass was $1.5 \mathrm{~kg}$ more in the anti-inflammatory diet group, compared to the proinflammatory diet group, with adjusted confounders

Table 1 Participant characteristics and body composition by DII Level

\begin{tabular}{lccc}
\hline Continuous variables (mean $\mathbf{H}$ S) & Anti-inflammatory diet & Pro-inflammatory diet & P value \\
\hline Age (year) & $37.60 \pm 7.58$ & $35.03 \pm 8.48$ & 0.105 \\
Weight $(\mathrm{kg})$ & $81.09 \pm 12.56$ & $80.61 \pm 12.09$ & 0.317 \\
Height $(\mathrm{cm})$ & $161.25 \pm 6.24$ & $161.33 \pm 5.75$ & 0.217 \\
BMl $\left(\mathrm{kg} / \mathrm{m}^{2}\right)$ & $30.94 \pm 3.99$ & $30.52 \pm 3.56$ & 0.130 \\
Waist circumference $(\mathrm{cm})$ & $99.25 \pm 10.24$ & $98.97 \pm 9.89$ & 0.391 \\
Body fat mass $(\mathrm{kg})$ & $33.98 \pm 8.55$ & $34.27 \pm 8.89$ & 0.858 \\
Visceral fat area(cm $\left.{ }^{2}\right)$ & $162.39 \pm 95.08$ & $175.145 \pm 10.75$ & 0.307 \\
Fat-free mass $(\mathrm{kg})$ & $47.6 \pm 20.03$ & $46.5 \pm 49.20$ & 0.021 \\
Physical activity (MET h/day) & $1162 / 45 \pm 1322 / 88$ & $773 / 24 \pm 692 / 04$ & $<0.0001$ \\
MCP-1 & $30.76 \pm 42.01$ & $51.72 \pm 67.13$ & $<0.0001$ \\
\hline
\end{tabular}

$\mathrm{n}=280$

Data are presented as mean \pm standard deviation

Nutrients intake adjusted for energy intake before calculating DII

DIl values were categorized according to the median (anti-inflammatory diet: DII $\leq 0.05$, pro-inflammatory

diet: DII>0.06)

Independent sample t-test was used for comparison of continuous variables between DII categories 
Table 2 DII food parameters intake according to DII group

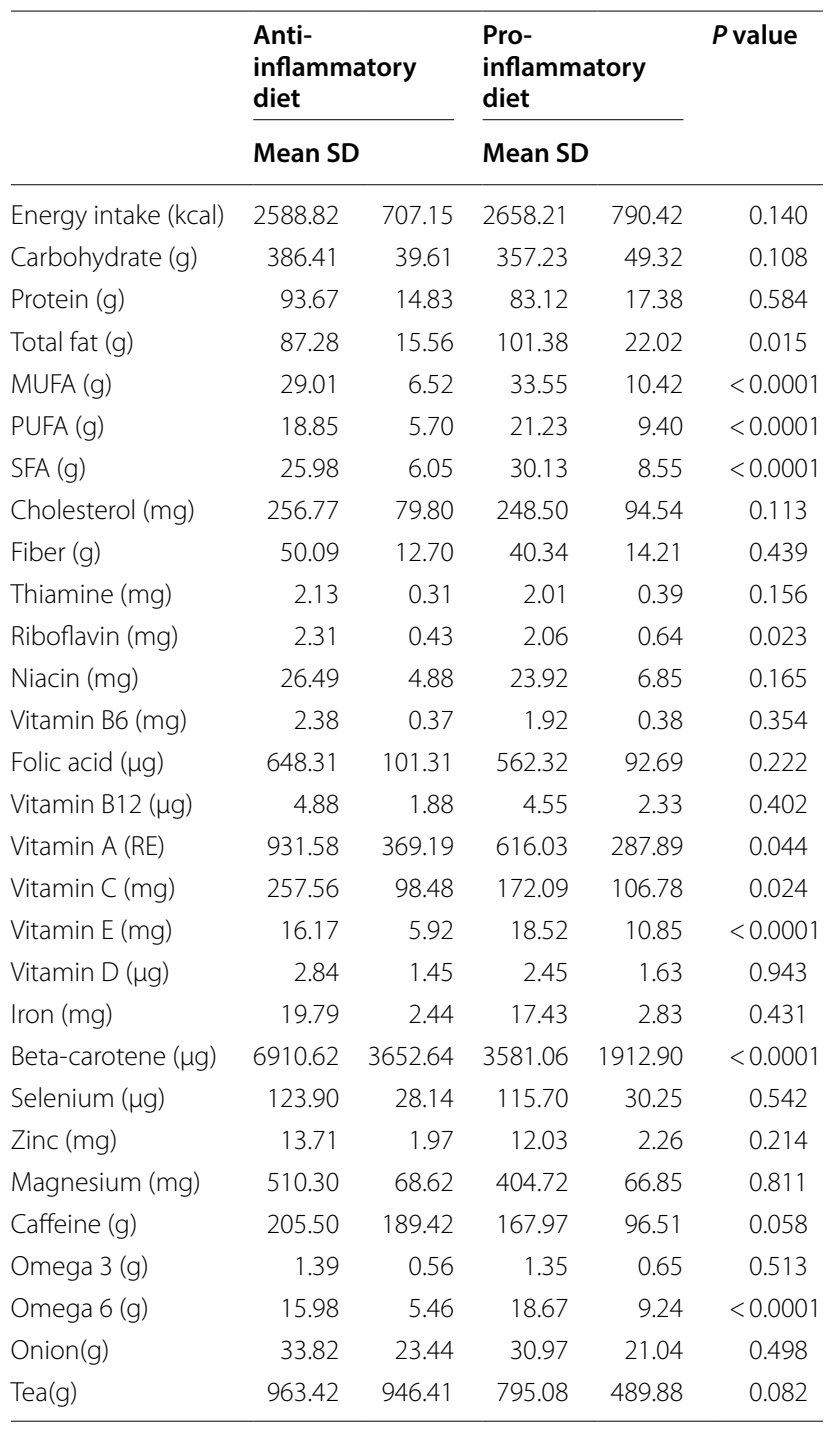

$\mathrm{n}=280$

Data are presented as mean \pm standard deviation

Comparisons of nutrient intake across the groups of the DII were analyzed using independent sample t-test

DII values were categorized according to the median (anti-inflammatory diet: DII $\leq 0.05$, pro-inflammatory

diet: DII >0.06)

Nutrients intake adjusted for energy intake

( $\beta=1.50,95 \%$ CI $0,3.01, P=0.05)$, fat mass was $0.14 \mathrm{~kg}$ lower in the anti-inflammatory diet group, with respect to the pro-inflammatory group, with adjusted covariates $(\beta=-0.142,95 \% \mathrm{CI}-4.44,-1.71, P=0.03)$. Linear regression tests demonstrated a positive relationship between DII and serum MCP-1 level after adjusting for confounders $(P=0.03)$. MCP-1 serum levels was 18.81 lower in the anti-inflammatory diet group, with respect to the pro-inflammatory group, with adjusted covariates $(\beta=-18.81,95 \% \mathrm{CI}-35.84$, $-1.79, P=0.03$ ) (Table 3).

\section{Discussion}

The current study set out to examine the associations between dietary inflammatory potential, body composition, and inflammation in Iranian obese women. Previous studies have shown that different dietary components have varying effects on body composition, and inflammation. In this cross-sectional study, it was found that subjects with a higher DII had lower fat-free mass and higher fat mass than others, independent of potential confounders. Furthermore, independent of confounders, the DII, and MCP-1 are related.

A dissident study in Spain demonstrated that a higher DII score was inversely associated with obesity-related parameters such as FFM and weight [29]. The previous papers have shown DII was related to higher average BMI, WC, and WHR [23, 30, 31]. The associations between fat mass, BMI, and waist circumference with inflammatory molecules such as IL-1, IL-6 have been suggested [32, $33]$. In this context, increased circulating cytokine levels, have been described in relation to a decrease in FFM [34]. A possible mechanism was theorized that a diet with an inflammation-induced potential is correlated with higher inflammatory response, and may result in lower fat-free mass. Furthermore, individuals with higher adherence to DII had a lower intake of some nutrients like vitamins $C$ and $\mathrm{E}$, magnesium, potassium, and a range of carotenoids such as Beta carotene that the amount of intake of these nutrients was positively associated with muscle mass in women. Moreover, based on previous evidence, higher adherence to the healthy dietary pattern as the Mediterranean Diet, Healthy Diet Indicator, Diet Quality Index, Alternate Healthy Eating Index, and DASH-style was significantly associated with measurements of muscle mass. Consumption of a variety of plant-based nutrients and overall higher quality in some dietary patterns resulted in the conservation of muscle mass [35]. M. Ruiz-Canela et al. shows participants with higher pro-inflammatory diet also had higher BMI and WHR [36]. Some potential mechanisms are hypothesized, such as activation of pathogen-associated molecular patterns, such as nod and toll-like receptors (TLRs), that induce the activation of inflammatory markers particularly in adipose tissues [37]. Also, intestinal microbiota may be affected by highfat or low-fiber dietary patterns, which also appear to be associated with low-grade inflammation and obesity [3840]. Evidence suggests that weight gain can be predicted by the proteins in plasma that are sensitive to inflammation [41]. Serine phosphorylation is another conceivable mechanism that assumes a function in inflammation. Inflammation causes phosphorylation of both insulin 
Table 3 The Association between DII, Fat-Free Mass, Fat Mass, and MCP-1

\begin{tabular}{llll}
\hline Variables & B & 95\% (Cl) & P value \\
\hline Fat free mass & & $(0.01,3.01)$ \\
Anti-inflammatory diet & 1.50 & Ref. \\
Pro-inflammatory diet & Ref. & $(-4.44,-0.171)$ \\
Fat mass & -0.142 & Ref. \\
Anti-inflammatory diet & Ref. & $(-35.84,-1.79)$ \\
Pro-inflammatory diet & & Ref. \\
MCP-1 & -18.81 & $0.030^{*}$ \\
Anti-inflammatory diet & Ref. & $0.030^{* *}$ \\
Pro-inflammatory diet & & \\
\hline
\end{tabular}

$\mathrm{n}=280$

DIl values were categorized according to the median

(Anti-inflammatory diet: $\mathrm{DII} \leq 0.05$, Pro-inflammatory diet: $\mathrm{DII}>0.06$ )

$P$ value*: adjusted for age, physical activity, economic and job status

$P$ value **: adjusted for age, weight, smoking, physical activity, economic and job status

receptor and its proteins substrate, including the enzyme phosphatidylinositol 3-OH kinase (PI3 K) bind together, then the inflammatory pathway, mainly I kappa B kinase (IKKb) and Nuclear factor-kappa B (NF-kB) pathway will be activated, finally inhibits insulin-mediated PI3K signaling [42]. IKKb/NF-kB activation also blocked cytokine signaling-3, a protein that blocks cell signals from insulin $[43,44]$. Ultimately, these processes trigger suppression of appetite [45].

This study was indicated that participants with higher DII had a greater level of MCP-1. In a study conducted in Belgium was seen that DII and inflammatory markers IL-6 have been associated. Although there were no significant associations between CRP and fibrinogen [46]. Moreover, Shivappa et al. showed that pro-inflammatory diets were related to increased levels of various inflammatory markers such as TNF- $\alpha$, IL-1, 2 , IFN- $\gamma$, and vascular cell adhesion molecules [47]. The research was conducted in Spain demonstrated that an anti-inflammatory diet, such as a Mediterranean diet, was associated with a significant reduction of IL-6, IL-8, and MCP-1 [48]. Therefore, one possible mechanism seems to suggest that anti-inflammatory diets can modify inflammatory responses, is due to their antioxidants, fiber content, and other anti-inflammatory substances $[19,48]$.

To the researchers' knowledge, this is the first study conducted which examines the association between dietary inflammatory potential, body composition, and MCP-1 levels.

\section{Conclusion}

The present results provide evidence supporting the proposition that a higher DII score (pro-inflammatory diet) is directly associated with lower fat-free mass, higher fat mass, and higher levels of inflammatory markers like MCP-1. These results suggest the importance of promoting dietary patterns with low inflammatory potential to reduce low-grade inflammation and improve obesity- parameters among the overweight and obese population.

\section{Limitations}

This study has several limitations. First, include the reliability and validity of the estimation of average food intakes, which were based on the relatively limited number of food items (147 items, which is moderately long for an FFQ). Second, the DII was calculated using the data on just 29 food parameters derived from the FFQ. Third, causality cannot be inferred, because of the crosssectional design of the study. Fourth, it is not possible to generalize about dietary patterns throughout the country, because dietary intakes and other lifestyle measurements in Tehran are somewhat different from those in other parts of the country. Moreover, these dietary patterns were confined to women.

\section{Abbreviations}

AHEl: Alternate Healthy Eating Index; BMI: Body mass index; CVD: Cardiovascular disease; CCR2: Chemokine receptor-2; CRP: C-reactive protein; DIl: Dietary inflammatory index; DQI: Diet Quality Index; ELISA: Enzyme-linked immunosorbent assay; FFQ: Food frequency questionnaire; FM: Fat mass; FFM: Fat-free mass; HTN: Hypertension; Hs-CRP: High-sensitivity C-reactive protein; HDI: Healthy Diet Indicator; IPAQ: International Physical Activity Questionnaires; IFN- $\gamma$ : Interferon-gamma; IL-2: Interleukin-2; IL-4: Interleukin-4; IL-6: Interleukin-6; IL-8: Interleukin-8; IL-10: Interleukin-10; IL-1ß: Interleukin-1ß; IKKb: I kappa B kinase; MCP-1: Monocyte Chemoattractant Protein-1; MUFA: Monounsaturated fatty acids; METs: Metabolic Equivalent Tasks; NF-kB: Nuclear factor kappa B; PUFA: Polyunsaturated fatty acids; PI3 K: Phosphatidylinositol 3-OH kinase; SFA: Saturated fatty acids; TNFa: Tumor necrosis factora; TC: Total cholesterol; TG: Triglycerides; WHO: World Health Organization; WHR: Waist to hip ratio; WAT: White adipose tissue. 


\section{Acknowledgements}

We are grateful to all of the participants for their contribution to this research. This study was supported by grants from the Tehran University of Medical Sciences, Tehran, Iran.

\section{Authors' contributions}

NG and ER designed the study and collected the samples, SFS and LS entering FFQ data into NUTRITIONIST IV software, AM and NB wrote the paper, MSY performed the statistical analyses, FSH revised the article, SAK contributed to interpretation of the data and revised the article, KhM had full access to all of the data in the study and took responsibility for the integrity and accuracy of the data. All authors read and approved the final manuscript.

\section{Funding}

This study is funded by grants from the Tehran University of Medical Sciences (TUMS), (Grant ID: 95-03-161-33142).

\section{Availability of data and materials}

Participants of this study did not agree for their data to be shared publicly, so supporting data is not available.

\section{Ethics approval and consent to participate}

Ethics approval for the study protocol was confirmed by The Human Ethics Committee of Tehran University of Medical Sciences (Ethics Number IR.TUMS. VCR.REC.1395.1597). All participants signed a written informed consent that was approved by the Ethics committee.

\section{Consent for publication}

Not applicable.

\section{Competing interests}

All authors declared that they have no competing interests.

\section{Author details}

${ }^{1}$ Department of Community Nutrition, School of Nutritional Sciences and Dietetics, Tehran University of Medical Sciences (TUMS), P.O. Box: 14155-6117, Tehran, Iran. ${ }^{2}$ Department of Epidemiology and Biostatistics, School of Public Health, Tehran University of Medical Sciences (TUMS), Tehran, Iran. ${ }^{3}$ Department of Clinical Nutrition, School of Nutritional Sciences and Dietetics, Tehran University of Medical Sciences, Tehran, Iran.

Received: 12 August 2020 Accepted: 13 November 2020 Published online: 23 November 2020

\section{References}

1. Gallus S, Lugo A, Murisic B, Bosetti C, Boffetta P, La Vecchia C. Overweight and obesity in 16 European countries. Eur J Nutr. 2015;54(5):679-89.

2. Finucane MM, Stevens GA, Cowan MJ, Danaei G, Lin JK, Paciorek CJ, et al. National, regional, and global trends in body-mass index since 1980: systematic analysis of health examination surveys and epidemiological studies with 960 country-years and 9.1 million participants. Lancet. 2011;377(9765):557-67.

3. Poston L, Caleyachetty R, Cnattingius S, Corvalán C, Uauy R, Herring S, et al. Preconceptional and maternal obesity: epidemiology and health consequences. Lancet Diabetes Endocrinol. 2016:4(12):1025-36.

4. Esser N, Legrand-Poels S, Piette J, Scheen AJ, Paquot N. Inflammation as a link between obesity, metabolic syndrome and type 2 diabetes. Diabetes Res Clin Pract. 2014;105(2):141-50

5. Ahluwalia N, Dalmasso P, Rasmussen M, Lipsky L, Currie C, Haug E, et al. Trends in overweight prevalence among 11-, 13-and 15-year-olds in 25 countries in Europe, Canada and USA from 2002 to 2010. Eur J Public Health. 2015;25(suppl 2):28-32.

6. Busetto L, Maggi S. Incidence and prevalence of obesity. Minimally Invasive Bariatric and Metabolic Surgery: Springer; 2015. p. 11-5.

7. Fierabracci P, Tamberi A, Santini F. Obesity-related comorbidities. Minimally Invasive Bariatric and Metabolic Surgery: Springer; 2015. p. 25-34.

8. Williams EP, Mesidor M, Winters K, Dubbert PM, Wyatt SB. Overweight and obesity: prevalence, consequences, and causes of a growing public health problem. Current obesity reports. 2015;4(3):363-70.
9. Calder PC, Ahluwalia N, Brouns F, Buetler T, Clement K, Cunningham K, et al. Dietary factors and low-grade inflammation in relation to overweight and obesity. Br J Nutr. 2011;106(S3):S1-78.

10. Sun S, Ji Y, Kersten S, Qi L. Mechanisms of inflammatory responses in obese adipose tissue. Annu Rev Nutr. 2012;32:261.

11. Rodríguez-Hernández H, Simental-Mendía LE, Rodríguez-Ramírez G, Reyes-Romero MA. Obesity and inflammation: epidemiology, risk factors, and markers of inflammation. Int J Endocrinol. 2013. https://doi. org/10.1155/2013/678159.

12. Fock KM, Khoo J. Diet and exercise in management of obesity and overweight. J Gastroenterol Hepatol. 2013;28(S4):59-63.

13. Chen A, Mumick S, Zhang C, Lamb J, Dai H, Weingarth D, et al. Diet induction of monocyte chemoattractant protein-1 and its impact on obesity. Obesity. 2005;13(8):1311-20.

14. Bastarrachea RA, Lopez-Alvarenga JC, Bolado-Garcia VE, Tellez-Mendoza $J$, Laviada-Molina H, Comuzzie AG. Macrophages, inflammation, adipose tissue, obesity and insulin resistance. Gac Med Mex. 2007;143(6):505-12.

15. Dawson J, Miltz W, Mir AK, Wiessner C. Targeting monocyte chemoattractant protein-1 signalling in disease. Expert opinion on therapeutic targets. 2003;7(1):35-48.

16. Niu J, Kolattukudy PE. Role of MCP-1 in cardiovascular disease: molecular mechanisms and clinical implications. Clin Sci. 2009;117(3):95-109.

17. Panee J. Monocyte Chemoattractant Protein 1 (MCP-1) in obesity and diabetes. Cytokine. 2012;60(1):1-12.

18. Camargo A, Delgado-Lista J, Garcia-Rios A, Cruz-Teno C, Yubero-Serrano EM, Perez-Martinez $P$, et al. Expression of proinflammatory, proatherogenic genes is reduced by the Mediterranean diet in elderly people. $\mathrm{Br} \mathrm{J}$ Nutr. 2012;108(3):500-8

19. Medina-Remón A, Casas R, Tressserra-Rimbau A, Ros E, Martínez-González MA, Fitó $M$, et al. Polyphenol intake from a Mediterranean diet decreases inflammatory biomarkers related to atherosclerosis: a substudy of the PREDIMED trial. Br J Clin Pharmacol. 2017;83(1):114-28.

20. Ricordi C, Garcia-Contreras M, Farnetti S. Diet and inflammation: possible effects on immunity, chronic diseases, and life span. J Am Coll Nutr. 2015;34(sup 1):10-3.

21. Tonstad S, Butler T, Yan R, Fraser GE. Type of vegetarian diet, body weight, and prevalence of type 2 diabetes. Diabetes Care. 2009;32(5):791-6.

22. Azadbakht $\mathrm{L}$, Esmaillzadeh A. Dietary diversity score is related to obesity and abdominal adiposity among Iranian female youth. Public health nutrition. 2011;14(1):62-9.

23. Ruiz-Canela M, Zazpe I, Shivappa N, Hebert JR, Sanchez-Tainta A, Corella $D$, et al. Dietary inflammatory index and anthropometric measures of obesity in a population sample at high cardiovascular risk from the PREDIMED (PREvencion con Dleta MEDiterranea) trial. Br J Nutr. 2015;113(6):984-95

24. Salehi-Abargouei A, Esmaillzadeh A, Azadbakht L, Keshteli AH, Feizi A, Feinle-Bisset $C$, et al. Nutrient patterns and their relation to general and abdominal obesity in Iranian adults: findings from the SEPAHAN study. Eur J Nutr. 2016;55(2):505-18

25. Mirmiran P, Esfahani FH, Mehrabi Y, Hedayati M, Azizi F. Reliability and relative validity of an FFQ for nutrients in the Tehran lipid and glucose study. Public health nutrition. 2010;13(5):654-62.

26. Ghaffarpour $M$, Houshiar-Rad A, Kianfar $\mathrm{H}$. The manual for household measures, cooking yields factors and edible portion of foods. Tehran Nashre Olume Keshavarzy. 1999;7:213.

27. Shivappa N, Steck SE, Hurley TG, Hussey JR, Hébert JR. Designing and developing a literature-derived, population-based dietary inflammatory index. Public health nutrition. 2014;17(8):1689-96.

28. Craig CL, Marshall AL, Sjorstrom M, Bauman AE, Booth ML, Ainsworth BE, et al. International physical activity questionnaire: 12-country reliability and validity. Med Sci Sports Exerc. 2003;35(8):1381-95.

29. Correa-Rodríguez M, Rueda-Medina B, González-Jiménez E, CorreaBautista JE, Ramírez-Vélez R, Schmidt-RioValle J. Dietary inflammatory index, bone health and body composition in a population of young adults: a cross-sectional study. Int J Food Sci Nutr. 2018. https://doi. org/10.1080/09637486.2018.1446915.

30. Ruiz-Canela M, Zazpe I, Shivappa N, Hebert JR, Sánchez-Tainta A, Corella $D$, et al. Dietary inflammatory index and anthropometric measures of obesity in a population sample at high cardiovascular risk from the PREDIMED (PREvencion con Dleta MEDiterranea) trial. Br J Nutr. 2015:113(6):984-95. 
31. Muhammad HFL, van Baak MA, Mariman EC, Sulistyoningrum DC, Huriyati $E$, Lee $Y Y$, et al. Dietary inflammatory index score and its association with body weight, blood pressure, lipid profile, and leptin in Indonesian adults. Nutrients. 2019;11(1):148.

32. Brinkley TE, Hsu F-C, Beavers KM, Church TS, Goodpaster BH, Stafford RS, et al. Total and abdominal adiposity are associated with inflammation in older adults using a factor analysis approach. J Gerontol Series A. 2012;67(10):1099-106

33. Cesari M, Kritchevsky SB, Baumgartner RN, Atkinson HH, Penninx BW, Lenchik L, et al. Sarcopenia, obesity, and inflammation - results from the trial of angiotensin converting enzyme inhibition and novel cardiovascular risk factors study. Am J Clin Nutr. 2005;82(2):428-34.

34. Londhe P, Guttridge DC. Inflammation induced loss of skeletal muscle. Bone. 2015;80:131-42.

35. Kelaiditi E. Diet, inflammation and skeletal muscle mass in women. Norwich: University of East Anglia; 2013.

36. Jin C, Flavell RA. Innate sensors of pathogen and stress: linking inflammation to obesity. J Allergy Clin Immunol. 2013;132(2):287-94.

37. Salas-Salvado J, Bullo M, Garcia-Lorda P, Figueredo R, Del Castillo D, Bonada A, et al. Subcutaneous adipose tissue cytokine production is not responsible for the restoration of systemic inflammation markers during weight loss. Int J Obes. 2006;30(12):1714-20.

38. Wu GD, Chen J, Hoffmann C, Bittinger K, Chen Y-Y, Keilbaugh SA, et al. Linking long-term dietary patterns with gut microbial enterotypes. Science. 2011;334(6052):105-8.

39. Martínez JA, Etxeberría U, Galar A, Milagro Fl. Role of dietary polyphenols and inflammatory processes on disease progression mediated by the gut microbiota. Rejuvenation Rese. 2013;16(5):435-7.

40. Chassaing B, Gewirtz AT. Gut microbiota, low-grade inflammation, and metabolic syndrome. Toxicol Pathol. 2014;42(1):49-53.

41. Engström G, Hedblad B, Stavenow L, Lind P, Janzon L, Lindgärde F. Inflammation-sensitive plasma proteins are associated with future weight gain. Diabetes. 2003;52(8):2097-101.
42. Kievit P, Howard JK, Badman MK, Balthasar N, Coppari R, Mori H, et al. Enhanced leptin sensitivity and improved glucose homeostasis in mice lacking suppressor of cytokine signaling-3 in POMC-expressing cells. Cell Metab. 2006;4(2):123-32.

43. McCormick SM, Gowda N, Fang JX, Heller NM. Suppressor of cytokine signaling (SOCS) 1 regulates interleukin-4 (IL-4)-activated insulin receptor substrate (IRS)-2 tyrosine phosphorylation in monocytes and macrophages via the proteasome. J Biol Chem. 2016;291(39):20574-87.

44. Ueki K, Kondo T, Kahn CR. Suppressor of cytokine signaling 1 (SOCS-1) and SOCS-3 cause insulin resistance through inhibition of tyrosine phosphorylation of insulin receptor substrate proteins by discrete mechanisms. Mol Cell Biol. 2005;25(19):8762.

45. Mars M, de Graaf C, van Rossum C, de Groot C, Seidell J, Kok F, editors, Leptin and appetite responses induced by a four-day energy restriction; preliminary results. Food Choice Wageningen; 2002. p. 247-247.

46. Shivappa N, Hébert JR, Rietzschel ER, De Buyzere ML, Langlois M, Debruyne $\mathrm{E}$, et al. Associations between dietary inflammatory index and inflammatory markers in the Asklepios Study. Br J Nutr. 2015;113(4):665-71.

47. Shivappa N, Hebert JR, Marcos A, Diaz LE, Gomez S, Nova E, et al. Association between dietary inflammatory index and inflammatory markers in the HELENA study. Mol Nutr Food Res. 2017;61 (6):1600707.

48. Casas R, Urpi-Sardà M, Sacanella E, Arranz S, Corella D, Castañer O, et al. Anti-inflammatory effects of the Mediterranean diet in the early and late stages of atheroma plaque development. Mediators inflamma. 2017;2017:3674390.

\section{Publisher's Note}

Springer Nature remains neutral with regard to jurisdictional claims in published maps and institutional affiliations.
Ready to submit your research? Choose BMC and benefit from:

- fast, convenient online submission

- thorough peer review by experienced researchers in your field

- rapid publication on acceptance

- support for research data, including large and complex data types

- gold Open Access which fosters wider collaboration and increased citations

- maximum visibility for your research: over 100M website views per year

At BMC, research is always in progress.

Learn more biomedcentral.com/submissions 